\title{
Liberation analysis of South African Middle group seam chromite ore processed with Vertical Shaft Impactor Crusher
}

\author{
Mashudu Maruli, Wille Nheta \\ University of Johannesburg \\ Mineral Processing and Technology Research centre \\ P.O.BOX 17011, Doornfontein 2028, Johannesburg, South Africa \\ Mmaruli30@gmail.com; wnheta@uj.ac.za
}

\begin{abstract}
In this study, the impact of vertical shaft impactor (VSI) crusher on fine and ultrafine production during crushing of South African Middle group (MG) chromite seam was investigated. The chromite ore was subjected to size reduction with VSI crusher at varied rotor tip speed $(30,35 \& 40 \mathrm{~Hz})$ and particle size distribution analysis was done on all the three products. The VSI crusher product particle size distribution indicated that as the VSI rotor speed was increased, the amount of ultrafine generated also increased. The product at rotor speed of $35 \mathrm{~Hz}$ revealed a lower percentage of ultrafines at $6.16 \%$ in the $-212+150 \mu \mathrm{m}$ and $0.85 \%$ in the $150+53 \mu \mathrm{m}$ particle size range. Ball mill product from the Plant was analysed and the results revealed that the ball mill is more efficient for chromite ore liberation as $84 \%$ of the $-425+300 \mu \mathrm{m}$ was produced compared to the VSI which only produced $51.27 \%-425+300 \mu \mathrm{m}$. However, the amount of ultrafines produced was high at $9.2 \%$ of $-150+106 \mu \mathrm{m}$ size fraction, with most ultrafine particle size of $4.42 \%$ in the $-53+26 \mu \mathrm{m}$ size fraction. The mineral liberation analysis conducted on the $-425+300$ and $-300+212 \mu \mathrm{m}$ VSI crusher products indicated that the degree of chromite liberation was higher at $95 \%$ on the $-300+212 \mu \mathrm{m}$ size fraction compared to $78 \%$ liberation on the $-425+300 \mu \mathrm{m}$ size fraction. From the liberation analysis conducted in this investigation, it can be concluded that VSI crusher has a greater potential in chromite size reduction as it has shown to produce a liberated product with reduced percentage of ultrafines. However more test needs to be done on the VSI residence time to improve the percentage mass of the required liberated product particle size.
\end{abstract}

Keywords: Chromite, Middle Group seam, Liberation, Ultrafine, Vertical shaft impactor crusher, Ball Mill

\section{Introduction}

Chromite is a very important mineral because it is the only economical viable source of chromium. It is used in various applications such as metallurgical industries, refractory industries and chemical industries [1]. Chromite ore is composed of elemental iron, oxygen and chromium and it is found in various forms, hence it is known as a spinel. Typical minerals that combines to form chromite spinel are magnesioferrite $\left(\mathrm{MgFe}_{2} \mathrm{O}_{4}\right)$, Fe-chromite $\left(\mathrm{FeCr}_{2} \mathrm{O}_{4}\right)$, magnesiochromite $\left(\mathrm{MgCr}_{2} \mathrm{O}_{4}\right)$, magnetite $\left(\mathrm{Fe}_{3} \mathrm{O}_{4}\right)$, and hercynite $\left(\mathrm{FeAl}_{2} \mathrm{O}_{4}\right)$ [2]. South African chromite occurs within the Bushveld Igneous Complex (BIC) [3]. There are various chromite seams within the BIC and these are the Lower Group (LG6), Middle Group (MG) and the Upper Group (UG) consecutively [4].

The common chromite beneficiation process begins with crushing of the run of mine (ROM) ore for particle size reduction to less than $3 \mathrm{~mm}$. Grinding/milling process is applied for further valuable mineral liberation to less than $1 \mathrm{~mm}$ followed by concentration of chromite valuable particles through gravity separation methods such as spiral concentrators, shaking tables and jigs. Comminution is a critical step during chromite beneficiation in order to achieve suitable particle size which will make it economically viable for subsequent beneficiation processes [5]. Tumbling ball mills are commonly used worldwide for the milling of chromite ores. Studies has shown that lots of ultrafine are generated during grinding with tumbling ball mills due to breakage rate within the ball mill operations [6,7]. Ultra-fines in chromite beneficiation results in loss of valuable chromite to tailings [5]. Ultra fines present in any milling product indicates that a lot of power or energy has been used during grinding process and this has negative economic impact due to the cost implications involved in producing an ultrafine product [8]. With gravity concentration involved in further chromite recovery downstream, particle size distribution is very critical because ultrafine material end up reporting to the tailings stream as a result of poor recovery during gravity concentration. 
Due to depreciation of chromite grades worldwide, it is of utmost importance to maximize chromite recoveries during processing in a convenient cost-effective manner. Therefore, this investigation focused on the effect of vertical impactor crusher on chromite liberation and recoveries using gravity separation. The main aim was to determine if the vertical impact crusher would produce a good liberated chromite product without generating excessive ultrafine particle sizes.

\section{Methodology}

The blended MG seam chromite ore (MG1, MG2, MG3 and MG4) obtained from the South African western limb of the Bushveld Igneous Complex (BIC) was subjected to size reduction on a VSI crusher. The ore samples were crushed at various VSI rotor speed of 30,35 and $35 \mathrm{~Hz}$ to assess the impact of rotor speed on the crusher product. The mass of the sample was kept at 10kg in the entire crushing tests. Particle size distribution (PSD) was done on the crushed ore from all the varied rotor speed experiments using $0.053,0.150,0.212,0.3,0.425,0.6,0.850,1.18$, $1.7,2.8,5.6,11.2 \& 13.3 \mathrm{~mm}$ sieve screens which were selected using the $\sqrt{2}$ method. Mineral Liberation analysis (MLA) was done on the $-425+300$ and $-300+212 \mu \mathrm{m}$ size fraction samples of the crusher product with the aim of determining the mineral that were associated with the chromite ore as well as the degree of chromite ore liberation. The PSD of the Plant ball mill product was also done in order to compare the distribution analysis compared to that of the VSI crusher using the same set of sieves. The surface morphology of the VSI crusher was done using a Scanning Electron Microscopy (SEM).

\section{Results and Discussion}

\subsection{Particle Size Distribution}

Figure 1 shows PSD of the MG chromite ore that was crushed at various VSI rotor speed. It can be seen that at higher rotor speed, more $\%$ of ultrafines were produced. The $\%$ of $-150+53 \mu \mathrm{m}$ size fraction produced were $0.85,2.34$ and $2.12 \%$ for $35,40 \& 45 \mathrm{~Hz}$ rotor speed respectively. This confirms work by Greg (2011) [9] who concluded that finer particle sizes are generated at moderately high rotor speed during Barmac operation. With reference to current operation in Metallurgical Plants for better chromite recovery, gravity circuits feed contains particle sizes of $100 \%$ passing $2000 \mu \mathrm{m}$ to $80 \%$ passing $450 \mu \mathrm{m}$. For minimised ultrafine generation, the VSI rotor speed of $35 \mathrm{~Hz}$ was the best. Figure 1 also shows that $75 \%$ passing $1700 \mu \mathrm{m}$ and $46 \%$ passing $425 \mu \mathrm{m}$ was achieved in

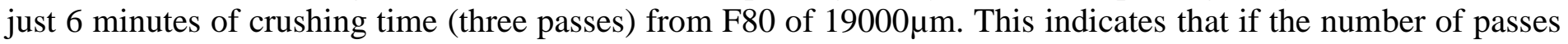
can be increased, higher desired particle size $\%$ can be achieved with reduced ultrafine production. Some plants have realized that about 30-45\% of ultrafine are generated during chromite beneficiation with ball mills [5]. Spirals have been reported to have lower efficiencies at particle sizes that are less than $100 \mu \mathrm{m}[10]$.

\subsection{Ball mill product particle size distribution}

Figure 2 shows a typical ball mill product PSD from the plant. The ball mill archived $84 \%$ of the $-425+300 \mu \mathrm{m}$ size range which is very efficient for chromite liberation. However, $9.2 \%$ of the $-106+80 \mu \mathrm{m}$ size fraction was produced which in this case is fine particles that results in poor spiral performance during chromite recovery . Compared to VSI crusher product PSD, ball mill produced a more liberated product but produced a higher \% of fine to ultrafines product. 


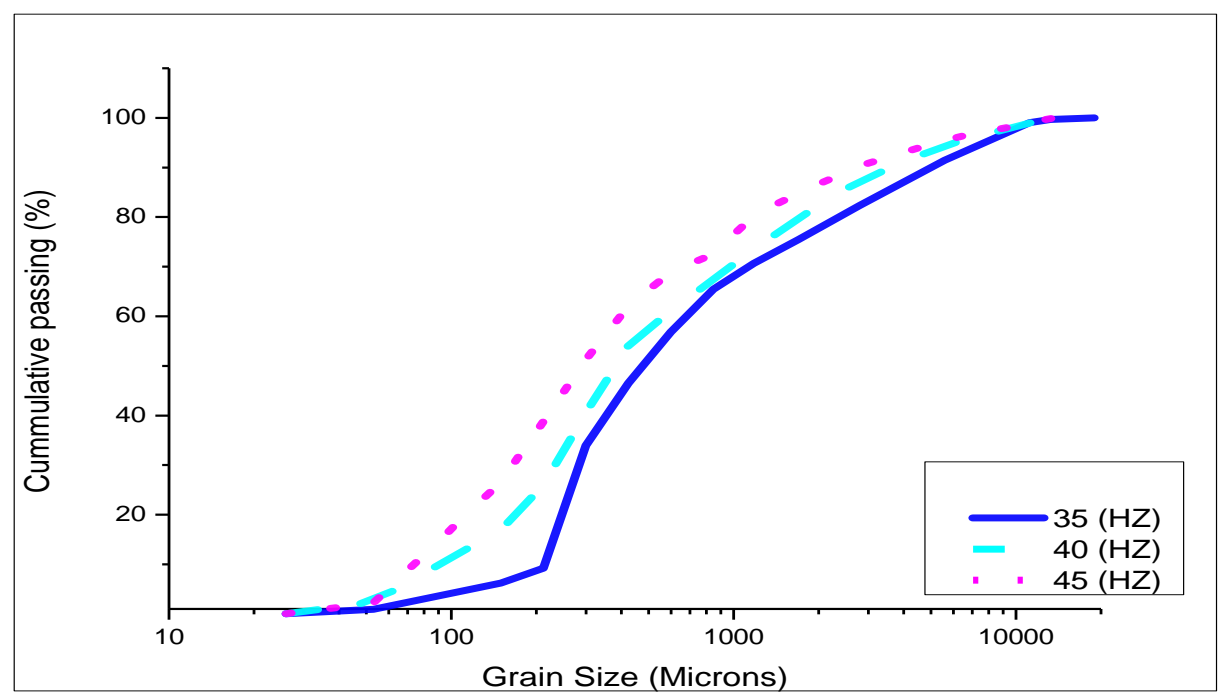

Figure 1: Particle Size Distribution of the VSI product at different rotor speed

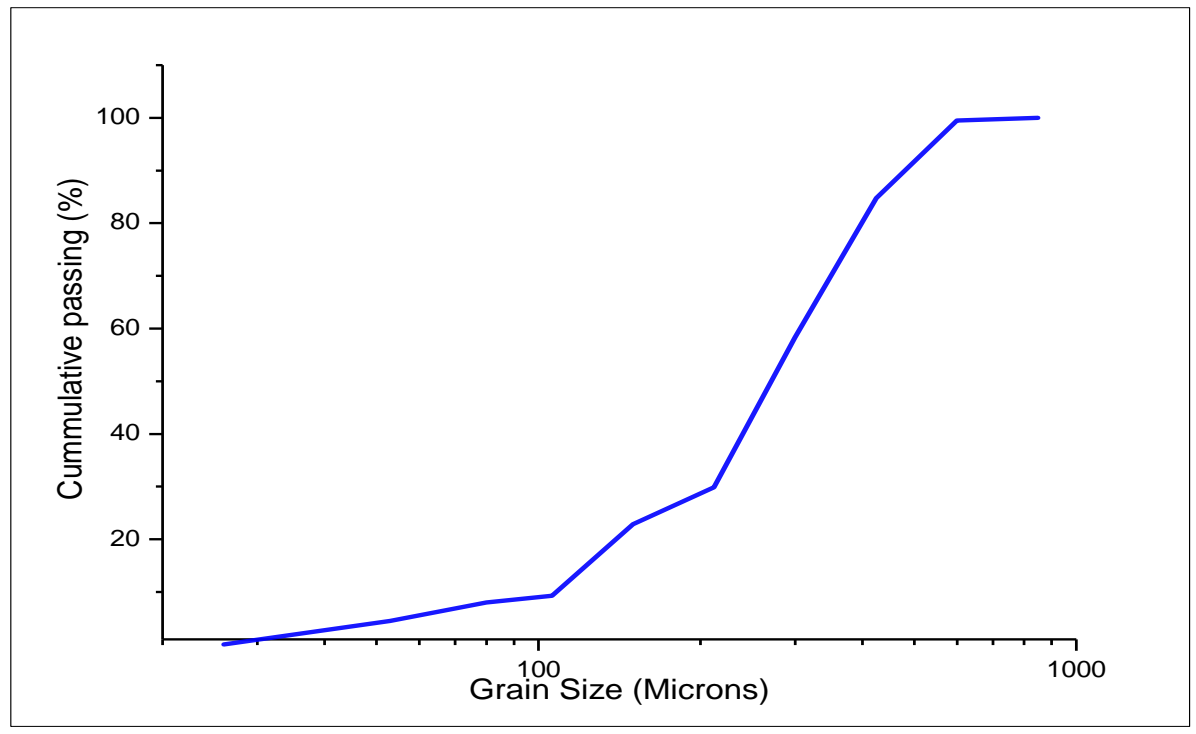

Figure 2: Particle Size Distribution of the Middle Group Ball mill product

\subsection{Mineral Association}

Figure 3 indicates the minerals that are associated with the MG seam chromite ore. The figure shows that chromite in this seam is mostly associated with plagioclase, pyroxene, amphibole and silicates and this confirms the results found by Kottke-levin, (2011) [3]. However, the amount of quartz is very low $(<1 \%)$ in both size fractions. 


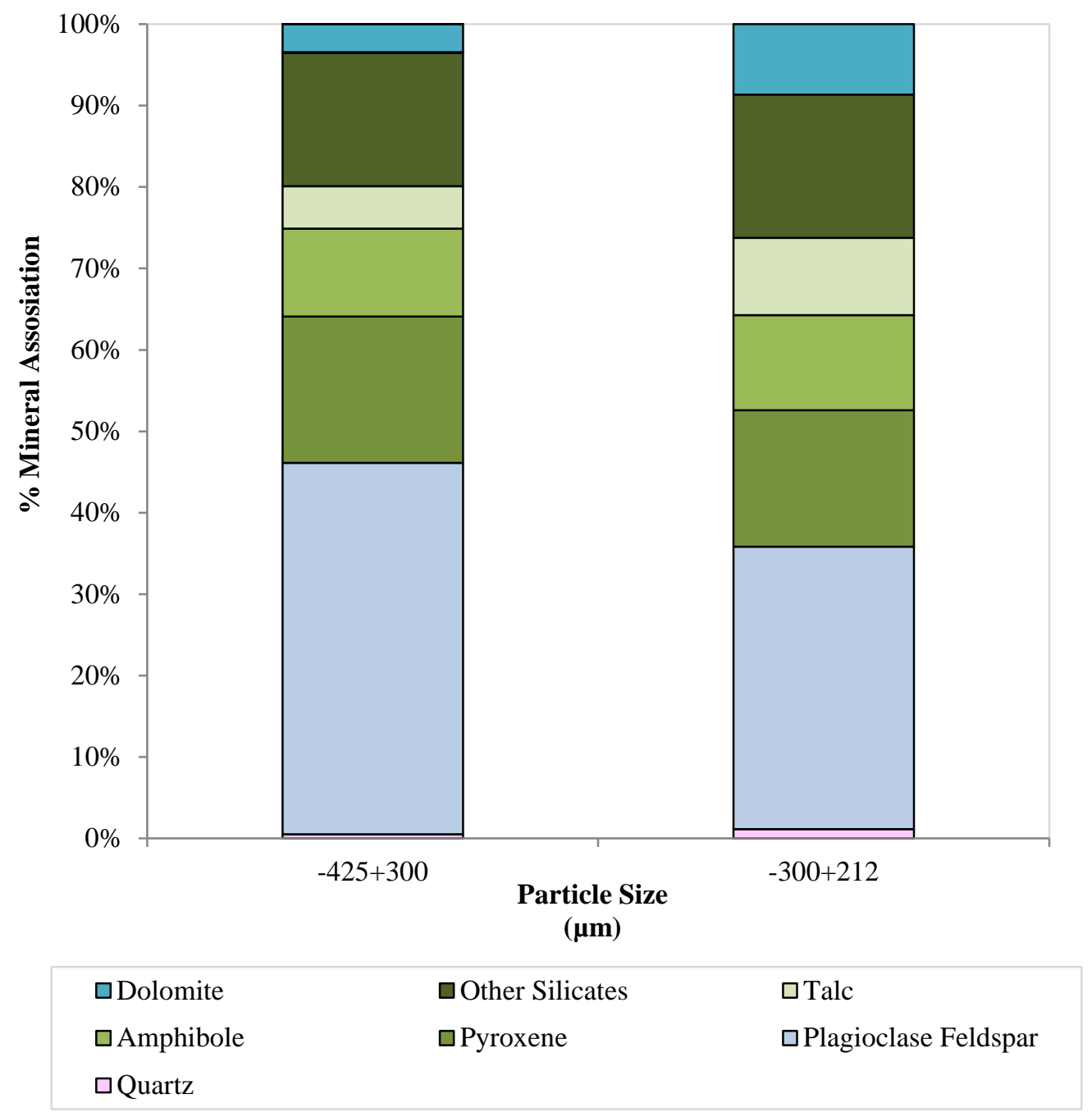

Figure 3: Middle Group Chromite Mineral association

\subsection{Surface morphology of VSI product}

Surface morphology of three different size fractions obtained after crushing was done using SEM and the results are shown in Figure 4. The fractions were $-0.6+0.425 \mathrm{~mm},-0.85+0.6 \mathrm{~mm}$ and $-1.18+0.85 \mathrm{~mm}$ represented by Figure $4 . \mathrm{A}, \mathrm{B}$ and $\mathrm{C}$ respectively. From Figure 4A, it can be seen that the $-0.6+0.425$ size fractions contains more liberated chromite grains, although there are some chromite grains which are still locked in silicates. This supports the reason why most plants are normally milling up to P95 of $-0.425 \mathrm{~mm}$ because at this stage the chromite starts to get liberated (Murthy et al., 2012). The morphology of Figure $4 \mathrm{~B}$ shows that the chromite is not yet liberated at that point since it is still associated by gangue material and so is Figure $4 \mathrm{C}$. The gangue material indicated by dark grey grains in all figures are associated with $\mathrm{Si}$ and $\mathrm{Al}$ and these are believed to be kaolinite [1]. 

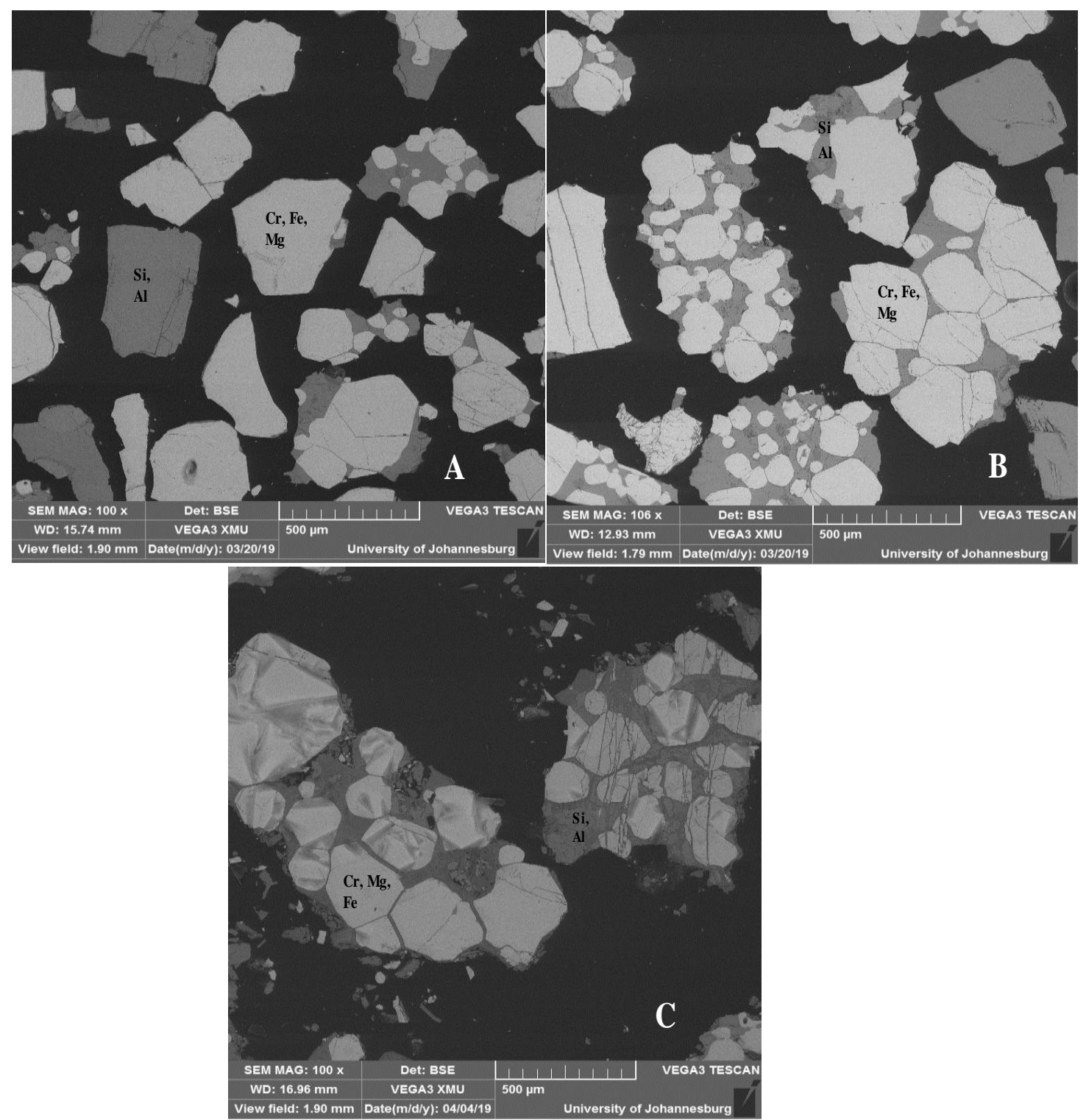

Figure 4: Surface morphology of the MG crushed product

\subsection{Degree of Chromite Liberation}

Figure 5 shows the degree chromite liberation after size reduction with VSI. It is clear that $95 \%$ of chromite is liberated at particle size fraction of $-300+212 \mu \mathrm{m}$ and this confirms the conclusions drawn by Aslan and Kaya, (2009) [11]. The degree of liberation at a grain size of $-425+300 \mu \mathrm{m}$ shows that about $78 \%$ of chromite is liberated which is less than that of $-300+212 \mu \mathrm{m}$. The majority of the unliberated chromite is sitting in the middling fraction, whilst the locked chromite potion is very minimal at $0.42 \%$ on the $-425+300 \mu \mathrm{m}$ and $0.18 \%$ on the $-300+212 \mu \mathrm{m}$ fraction. The entire degree of liberation analysis supports the reason behind plant targeting a mill discharge particle size of about $95 \%$ passing the $425 \mu \mathrm{m}$. 


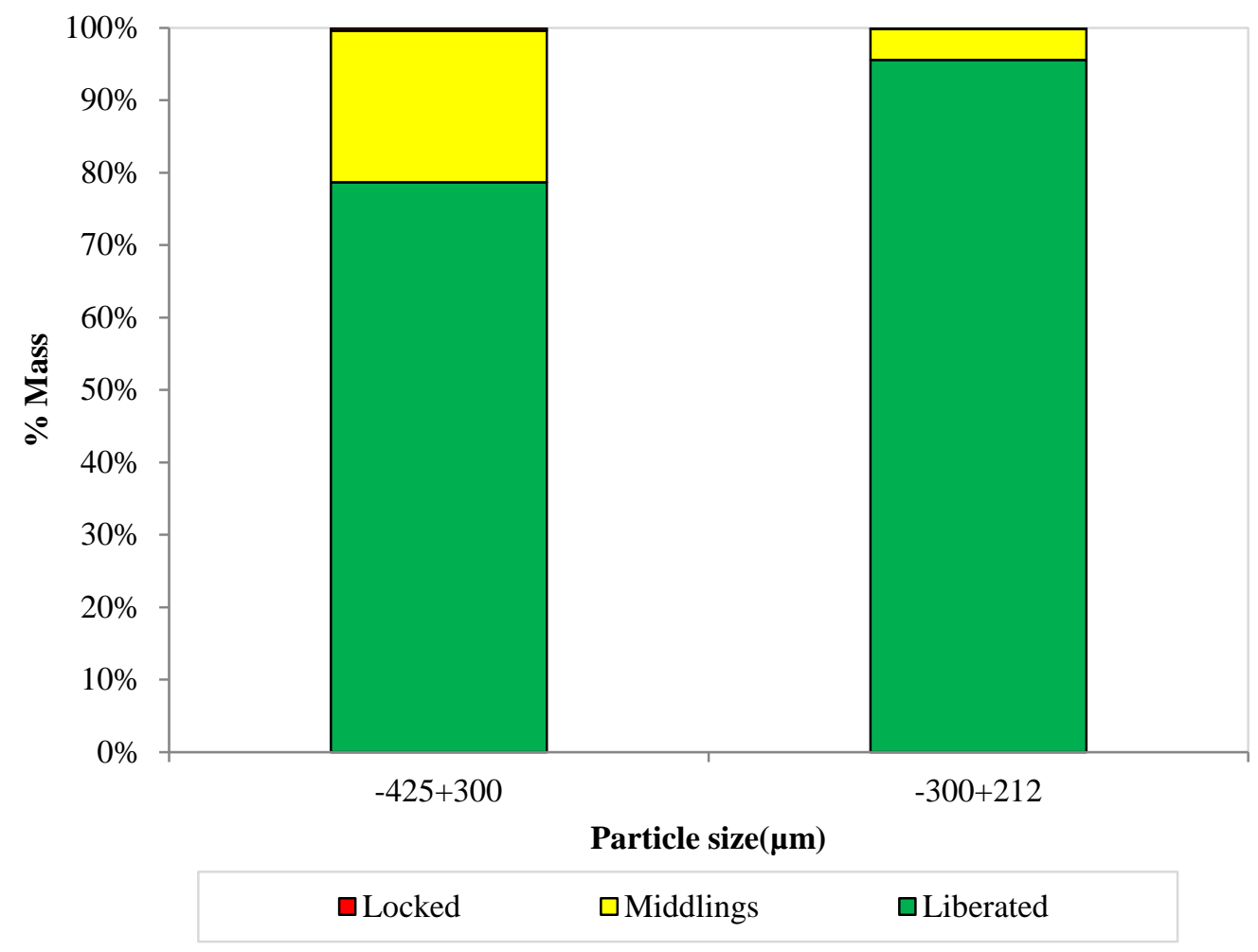

Figure 5: Degree of MG Chromite liberation analysis

\section{Conclusion}

This paper has presented the effect of using a VSI crusher on the comminution of Middle group chromite ore. VSI crusher produces a product that contains less fines and ultrafines at $6.16 \%$ in the $-212+150 \mu \mathrm{m}$ size range and $0.85 \%$ in the $-150+53 \mu \mathrm{m}$ size range. The ball mill produced excessive fine to ultrafine particles at $9.2 \%$ of $-150+106 \mu \mathrm{m}$ size fraction, with most ultrafine particle size of $4.42 \%$ of the $-53+26 \mu \mathrm{m}$ fraction. The ball mill PSD analysis showed that ball mill was more efficient as it produced a more liberated chromite ore at $84 \%$ of the $-425+300 \mu \mathrm{m}$ particle size as compared to the VSI crusher which only produced 51.27\% $-425+300 \mu \mathrm{m}$. From Mineral Liberation Analysis (MLA), it was concluded that indeed MG chromite begins to be liberated at $-425+300 \mu \mathrm{m}$ and evenly much better at $-300+212 \mu \mathrm{m}$ as Chromite showed to be 78 and $95 \%$ liberated at both size fractions respectively.

\section{Acknowledgements}

Acknowledgement is given to Thaba Cronimet Mine for the sample provided and the University of Johannesburg for laboratory facilities.

\section{References}

[1] Y. R. Murthy, S. K. Tripathy and C. R. Kumar, "Chrome ore beneficiation challenges and opportunities", Minerals Engineering, vol 24, no 5, pp 375-380, 2011

[2] M.Pedrotti, "Chromite : from the mineral to the commodity," 2012.

[3] J. Kottke-levin, "A geochemical study of the Middle Group chromitites", DEd thesis, University of Free State. 
[4] SSI Holdings, "The South African chrome industry," 2014.

[5] S. K. Tripathy, Y. R. Murthy, V. Singh, A. Srinivasulu, A. Ranjan, and P. K. Satija, "Performance optimization of an

industrial ball mill for chromite processing," J. South. African Inst. Min. Metall., vol. 117, no. 1, pp. 7581, 2017.

[6] N. Chimwani, T. Mohale and M. Bwalya, "Tailoring ball mill feed size distribution for the production of a size-graded product”, Minerals Engineering, Vol. 141, pp. 105891, 2019.

[7] H. Hanumanthappa, H. Vardhan, G.R Mandela, M. Kaza, R. Sah and B.K.H. Shanmugam, "A comparative study on a newly designed ball mill and the conventional ball mill performance with respect to the particle size distribution and recirculating load at the discharge end", Minerals Engineering, Vol. 145, pp. 106091, 2020.

[8] J. Allen, and C. Ntsele, "Technology selection of stirred mills for energy efficiency in primary and regrinding applications for the platinum industry", South African Institute of Mining and Metallurgy, pp.781-808, 2012.

[9] A. Greg, Crushing and Screening Handbook. $5^{\text {th }}$ ed. Metso, 2011.

[10] N. Aslan, and H. Kaya, "Beneficiation of chromite concentration waste by multi-gravity separator and high-intensity induced-roll magnetic separator", Arabian Journal for Science and Engineering, vol. 34, no.2B, pp. 285-297, 2009. 